
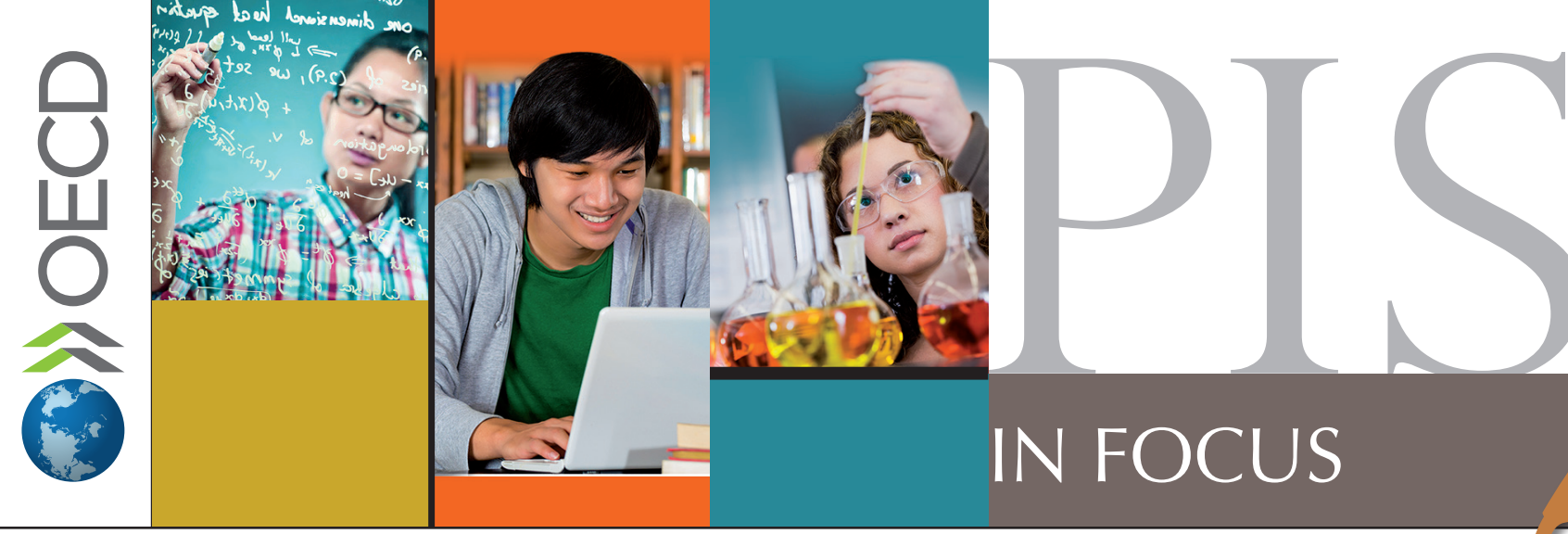

education data education evidence education policy education analysis education statistics education data education

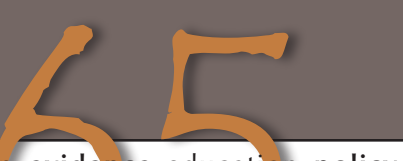

\title{
Should all students be taught complex mathematics?
}

- Exposure to complex mathematics concepts and tasks is related to higher performance in PISA among all students, including socio-economically disadvantaged students.

- Working on complex problems without individualised support can increase mathematics anxiety among weaker students.

- In most PISA-participating countries and economies, at least one in two students attends schools where teachers believe that it is best to adapt academic standards to the students' needs.

- Teaching strategies that support struggling students in mixed classes, such as giving students extra help when they need it, are related to students having more confidence in their mathematics ability.

Many mathematics teachers teach diverse classes, where students with limited knowledge of mathematics and low self-confidence work alongside others with advanced understanding and high motivation. While it is difficult, in these classes, for teachers to inspire all students to work to their full potential, it is not impossible. Gaps in students' knowledge and self-confidence, often related to socio-economic status, can be bridged through effective and equitable teaching. A big part of the solution is to stop classifying students as smart or dumb, quick or slow, and start sending frequent messages that success in mathematics comes from working hard, asking questions, and continually setting the next goal a little higher than the one just achieved.

The PISA report, Equations and Inequalities: Making Mathematics Accessible to All, looks at how teaching content and methods are related to students' performance and to their attitudes towards mathematics in 2012. One key finding of the report is that the more students are exposed to complex mathematics concepts and tasks, the better they perform on PISA applied mathematics problems (see PISA in Focus no. 63). A recipe to improve performance in PISA would thus be to make sure that all students are taught complex mathematics. But even this simple recipe can turn out half-baked if offering a more challenging curriculum to all students is not paired with greater and individualised support to struggling students.

Weak students can be more anxious when exposed to complex mathematics.

Failing to pay attention to the difficulties weaker students may have in performing computations, making connections, transferring knowledge and understanding the language of mathematics might alienate some students from a subject that is critically important for their future. The weakest students in the classroom are those more at risk of getting lost during the transition to difficult mathematics. 
On average across OECD countries, greater exposure to complex concepts, as measured by the PISA index of familiarity with mathematics, is associated with higher anxiety towards mathematics among students who score in the bottom quarter of mathematics performance and with lower anxiety among students who score in the top quarter.

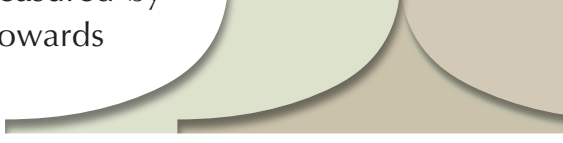

Teaching complex mathematics topics thus tends to reinforce the self-confidence and reduce the anxiety of students who are relatively well-prepared and ready to be challenged, but it may undermine the self-beliefs of weaker students if they are not given adequate support to discover and work with complex concepts. The association between exposure to complex mathematics and mathematics anxiety is particularly strong among low-achieving students in Austria and the Czech Republic.

\section{Familiarity with mathematics and mathematics anxiety, by students' performance in mathematics Change in mathematics anxiety associated with greater familiarity with mathematics, among the lowest and highest performers in mathematics}

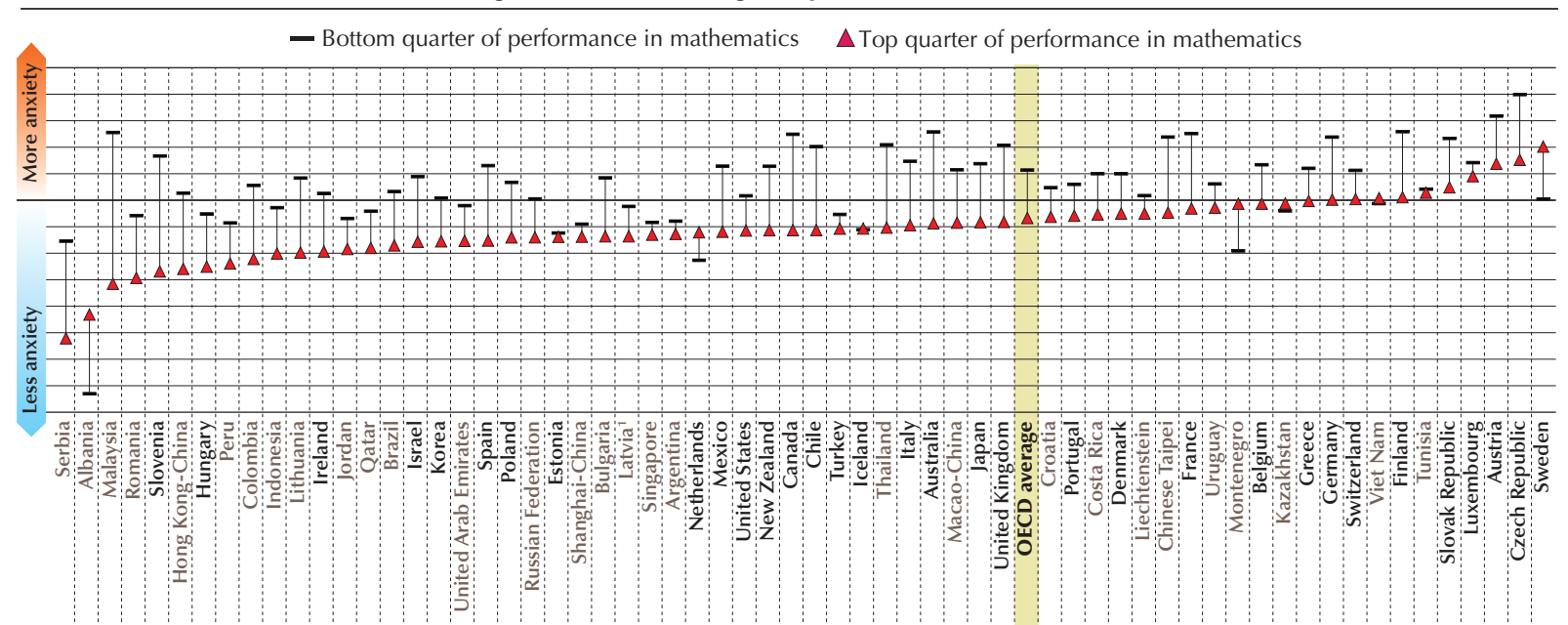

Notes: The index of mathematics anxiety is based on the degree to which students agreed with the statements: I often worry that it will be difficult for me in mathematics classes; I get very tense when I have to do mathematics homework; I get very nervous doing mathematics problems; I feel helpless when doing a mathematics problem; and I worry that I will get poor marks in mathematics.

The index of familiarity with mathematics is based on students' responses to 13 items measuring students' self-reported familiarity with mathematics concepts (such as exponential function, divisor, quadratic function, etc.).

1. Latvia acceded to the OECD on 1 July 2016. The OECD average does not include Latvia.

Countries and economies are ranked in ascending order of the index change among the students in the top quarter of performance in mathematics. Source: OECD, PISA 2012 Database.

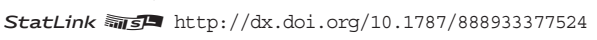

\section{Teachers believe it is best to adapt instruction to what their students can do.}

According to principals' reports, on average across OECD countries, about $70 \%$ of students attend schools where teachers believe that it is best to adapt academic standards to students' capacities and needs. Heterogeneity seems to be more of a problem in disadvantaged schools, where some students have a poor understanding of mathematics and minimal skills in the subject. Teachers in disadvantaged schools are more likely than those in advantaged schools to agree that the content of instruction should be adapted to what students can do. In Germany, for example, $51 \%$ of principals of disadvantaged schools reported that teachers are willing to adapt their standards, while only $13 \%$ of principals of advantaged schools so reported.

How do teachers adapt their instruction in mixed classes? One strategy is to assign different tasks to students with different levels of preparation. About 30\% of students, on average across OECD countries, reported that teachers in their school differentiate between students when assigning tasks. Again, task differentiation is more frequently practiced in disadvantaged than in advantaged schools, and particularly so in Austria, Bulgaria, Germany, the Netherlands, Portugal, Romania, Serbia, the Slovak Republic, Slovenia and the United Arab Emirates. 
Teachers assigning different tasks to students based on their capacities, by schools' socio-economic profile Percentage of students who reported that teachers in their school differentiate between students when assigning tasks in most or every lesson

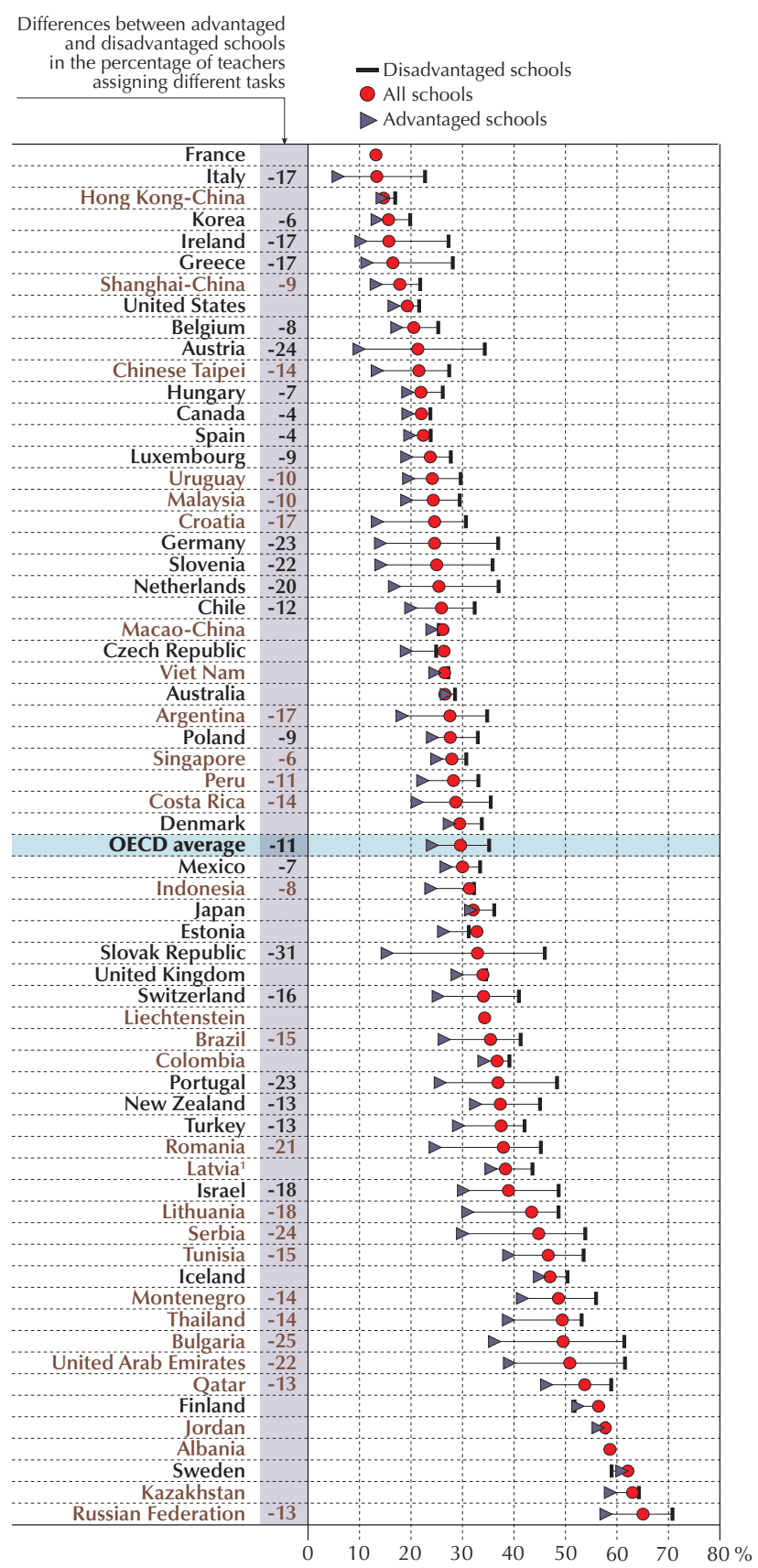

Notes: Task differentiation by teachers is measured on the basis of students self-reports.

Disadvantaged (advantaged) schools are those schools whose mean PISA index of economic, social and cultural status is statistically lower (higher) than the mean index across all schools in the country/economy.

Statistically significant percentage-point differences between advantaged and disadvantaged schools are shown next to the country/economy name.

1. Latvia acceded to the OECD on 1 July 2016. The OECD average does not include Latvia.

Countries and economies are ranked in ascending order of the percentage of students in all schools where teachers differentiate between students when giving tasks.

Source: OECD, PISA 2012 Database.

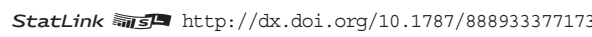

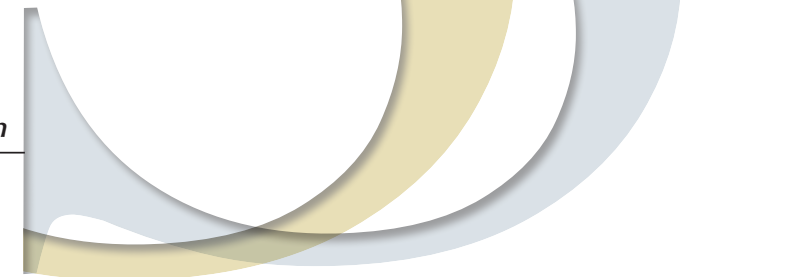

In the majority of countries and economies that participated in PISA 2012, students' confidence in their own mathematics abilities tends to be greater when the teacher gives different work to those who have difficulties learning and/or to those who can advance faster. At the same time, if the differentiation of tasks within the classroom is too rigid, the practice can prevent low-achieving students from having the same opportunities to learn as higher-achieving students, and lead to the same kind of segregation in outcomes that result from more radical forms of tracking and streaming. Flexible methods of differentiation, where learning groups in class are frequently reconfigured on the basis of continuous evaluations, can reduce the segregation that often comes with more rigid forms of grouping. Flexible grouping, particularly if it is combined with co-operative teaching methods, might also give the right incentives to weaker students by embodying the idea that ability is not fixed, and that everyone has something important to offer when working on mathematics problems.

Supportive teaching practices, in novative pedagogies and curriculum design make a difference

in mixed classes.

The way teachers communicate and structure their lessons is likely to be as important as teaching content in shaping students' attitudes towards mathematics. In particular, in all countries and economies, providing additional support to struggling students is strongly related to students' positive self-beliefs. High-dose, targeted tutoring can help struggling students acquire the numerical and spatial skills they may not have developed before, without denying them exposure to a more demanding curriculum. More frequent use of problem solving as a method of teaching mathematics can also help weaker students to connect the abstract or conceptual aspects of mathematics with real life, and make mathematics lessons more engaging for all students. All of these teaching practices are easier to use when curriculum frameworks allocate sufficient time to a focused set of big mathematical ideas and provide students with multiple opportunities to learn them at varying levels of complexity. 


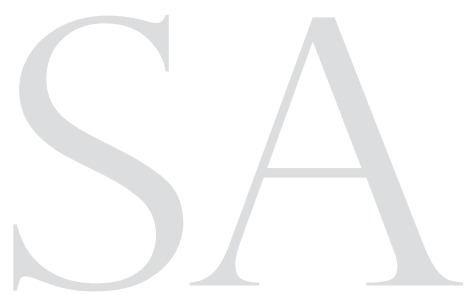

Relationship between teaching practices and students' mathematics self-concept

Change in the index of mathematics self-concept associated with teachers engaging in the following practices in most or every lesson:

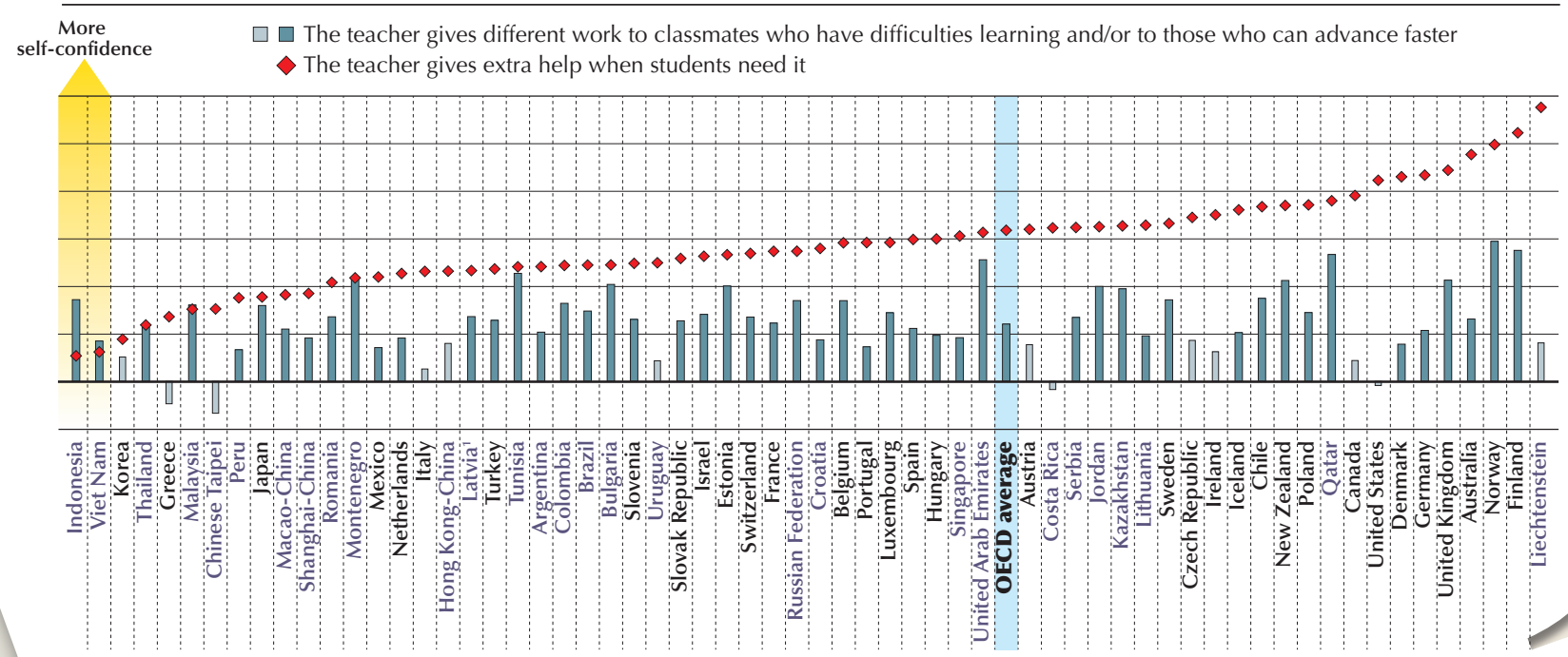

Notes: The index of mathematics self-concept is based on the degree to which students agreed with the statements: I'm just not good in mathematics; I get good grades in mathematics; I learn mathematics quickly; I have always believed that mathematics is one of my best subjects and In my mathematics class, I understand even the most difficult work.

The results take into account students' gender and socio-economic status.

Values that are statistically significant are indicated in bold.

1. Latvia acceded to the OECD on 1 July 2016. The OECD average does not include Latvia.

Countries and economies are ranked in ascending order of the change in the index of mathematics self-concept associated with teachers giving extra help when students need it in most or every lesson. Source: OECD, PISA 2012 Database.

The bottom line: Giving all students similar opportunities to learn complex mathematics is a key strategy for tackling low performance and increasing equity. The difficulties and anxiety some students experience when facing complex mathematics should not be a reason to lower expectations, stream students who have not yet acquired certain skills into inferior mathematics programmes, or water down the content of instruction. Teachers need to have the resources, pedagogical tools and dispositions to teach heterogeneous classes effectively and provide additional support to struggling students. If teachers choose to differentiate instruction within their classes, they can opt for methods that do not segregate weak students further, such as flexible grouping.

For more information

Contact Mario Piacentini (Mario.Piacentini@oecd.org)

See OECD (2016), Equations and Inequalities: Making Mathematics Accessible to All, PISA, OECD Publishing, Paris.

\begin{tabular}{l|l}
\hline Visit & Coming next \\
www.pisa.oecd.org & How does PISA assess scientific literacy? \\
www.oecd.org/pisa/infocus \\
Adults in Focus \\
$\underline{\text { Education Indicators in Focus }}$ \\
\hline Teaching in Focus
\end{tabular}

Photo credits: $\odot$ khoa vu/Flickr/Getty Images $\odot$ Shutterstock/Kzenon $\odot$ Simon Jarratt/Corbis

This paper is published under the responsibility of the Secretary-General of the OECD. The opinions expressed and the arguments employed herein do not necessarily reflect the official views of OECD member countries.

This document and any map included herein are without prejudice to the status of or sovereignty over any territory, to the delimitation of international frontiers and boundaries and to the name of any territory, city or area.

The statistical data for Israel are supplied by and under the responsibility of the relevant Israeli authorities. The use of such data by the OECD is without prejudice to the status of the Golan Heights, East Jerusalem and Israeli settlements in the West Bank under the terms of international law. 